\title{
Probiotic Use in Celiac Disease: Results from a National Survey
}

\author{
Andrew M. Joelson ${ }^{1}$, Alexa M Choy ${ }^{2}$, John W. Blackett ${ }^{1}$, Rebecca L. Molinsky ${ }^{3}$, Marilyn G. Geller ${ }^{4}$, Peter H. Green ${ }^{1,5}$, \\ Benjamin Lebwohl ${ }^{1,5}$
}

1) Division of Digestive and

Liver Diseases, Department

of Medicine, Columbia

University Medical Center,

New York;

2) Department of Medicine,

Columbia University Medical

Center, New York;

3) Department of

Epidemiology and Community

Health, University of

Minnesota, Minneapolis, MN;

4) Celiac Disease Foundation,

Woodland Hills, CA;

5) Celiac Disease Center,

Department of Medicine,

Columbia University Medical

Center, New York, USA

\author{
Address for correspondence: \\ Benjamin Lebwohl \\ The Celiac Disease Center at \\ Columbia University \\ 180 Fort Washington Avenue, \\ Suite 936 \\ New York, NY 10032 \\ BL114@columbia.edu
}

\begin{abstract}
Background \& Aims: Patients with celiac disease (CD) commonly use supplements for perceived health benefits despite scant evidence. We aimed to characterize the prevalence and predictors of probiotic use among CD patients.

Methods: We analyzed data from iCureCeliac ${ }^{\oplus}$; a patient-powered research network questionnaire distributed by the Celiac Disease Foundation. We included adults with self-reported CD who answered questions regarding demographics, diagnosis, symptoms, and treatment. We compared probiotic users versus probiotic non-users and subsequently performed multivariable logistic regression, assessing for independent predictors of probiotic use.

Results: 4,909 patients met the criteria for inclusion in the study. Of these, 1,160 (23.6\%) responded to a question regarding probiotic use. The mean age of participants was 38.8 years and $82 \%$ were female. 381 patients (33\%) reported using probiotics. More probiotic users sought nutritional counseling at time of diagnosis (36\% vs. $30 \%, \mathrm{p}=0.05)$ and remained symptomatic despite a gluten-free $\operatorname{diet}(40 \%$ vs. $25 \%, \mathrm{p}<0.001)$. Probiotic users had worse scores on the pain subscale of the SF36 (63.7 \pm 21.6 vs. $69.5 \pm 22.1, \mathrm{p}=0.006)$. On multivariable analysis, patients diagnosed after age 50 (OR=2.04, 95\%CI: 1.37-3.04), and those with persistent symptoms despite a gluten-free diet $(\mathrm{OR}=1.94,95 \% \mathrm{CI}$ : 1.44-2.63) were more likely to use probiotics.

Discussion: In this large study of a national CD registry, roughly one-third of CD patients reported using probiotics. Patients diagnosed later in life were more likely to use probiotics and those who remained symptomatic despite a gluten-free diet were twice as likely to take probiotics. Patients may be seeking additional means of treatment for persistent symptoms.
\end{abstract}

Key words: celiac disease - probiotics - gluten free diet - biopsy - dietary supplement.

Abbreviations: CD: celiac disease; CDQOL: Celiac Disease Quality of Life; GFD: gluten-free diet; PPRN: patient-powered research network; SF: short form.

\section{INTRODUCTION}

Celiac disease $(\mathrm{CD})$ is an immune-mediated enteropathy triggered by gluten ingestion in genetically susceptible individuals [1]. Celiac disease affects $0.7-1 \%$ of Americans, making it one of the most common inflammatory conditions of the digestive system in the United States [2, $3]$. The primary treatment for $\mathrm{CD}$ is complete abstinence from dietary products containing gluten. Yet, maintaining a strict gluten-free diet (GFD) is challenging for many individuals, and at least a quarter of adult CD patients report persistent symptoms despite strict adherence $[4,5]$. At present, there is limited evidence for additional therapeutic options [6]. However, there has been increasing interest among patients with $\mathrm{CD}$ to take dietary supplements for perceived health benefits [7].

Probiotics have gained significant popularity among patients with $\mathrm{CD}$ and in the general population $[7,8]$. Probiotics are live, ingestible microorganisms that can alter the gastrointestinal microbiome and may confer health benefits onto their host [9]. Despite the many studies examining their use, there is scant high-quality evidence supporting the use of probiotics in gastrointestinal disease. Guidelines issued by the American Gastroenterological Association (AGA) give conditional recommendations for the use of probiotics for 
the prevention of Clostridium difficile infection, pouchitis in surgically resected inflammatory bowel disease patients, and necrotizing enterocolitis, though the quality of supporting evidence remains limited [8].

Celiac disease and other autoimmune disorders of the gut are associated with abnormal composition and function of the intestinal microbiome [10]. It has been hypothesized that probiotic supplementation may have an impact on CD pathophysiology via three potential mechanisms: (1) digestion of gluten proteins, (2) maintenance of the intestinal barrier by preventing access of immunogenic polypeptides to lamina propria and (3) restoration of gut microbial homeostasis and regulation of the innate and adaptive immune systems [11]. There is currently a paucity of evidence supporting the use of probiotics to improve histopathologic or clinical manifestations of CD. Nevertheless, probiotics are among the most frequently used supplements in patients with CD for unclear reasons [7].

The aim of this study was to characterize the prevalence and predictors of probiotic use among CD patients using data from iCureCeliacTM, a voluntary, patient-powered research network questionnaire distributed by the Celiac Disease Foundation.

\section{METHODS}

\section{Study Design}

We performed a cross-sectional analysis utilizing questionnaire data from iCureCeliac ${ }^{\circledR}$ a voluntary, patientpowered research network (PPRN). Beginning in January 2016, the questionnaire was distributed to patients via the Celiac Disease Foundation website. Patients had the option to enter as much or as little data as they desired on an entirely voluntary basis with no financial incentive offered. Informed consent was obtained from each patient prior to completion of the survey. We included patients 18 years or older who indicated a diagnosis of $\mathrm{CD}$ in the questionnaire and who answered questions regarding probiotic use, symptoms, the method of diagnosis, and adherence to treatment that applied to our study question between the inception of the PPRN on January 30 , 2016 and February 21, 2019. This study was approved by the Institutional Review Board of Columbia University Medical Center on July $21^{\text {st }}, 2017$.

\section{Data Collection}

We collected basic demographic information including age, gender, age at diagnosis, country of origin, and region within the United States. Data regarding patients' diagnosis were also extracted from the survey including means of diagnosis, whether the diagnosis was made by a physician or non-physician health care practitioner, where patients obtained their primary information about celiac disease, whether patients sought nutritional counseling at time of diagnosis, the Short Form (SF) 36 questionnaire, and the Celiac Disease Quality of Life (CDQOL) score. We also examined information about self-rated health on a 5-point scale, GFD adherence, and persistent symptoms despite adherence to a GFD.

\section{Celiac Disease Quality of Life Score}

The CD-QOL score, was previously developed by Dorn et al. [12] through focus groups, expert review, and pilot testing.
It was shown to have high internal consistency and reliability. The final score contains 20 items in four domains (limitations, dysphoria, health concerns, inadequate treatment) with higher scores corresponding to better health states.

\section{SF-36}

The SF-36, first described by Ware and Sherbourne [13], is a 36-question survey incorporating 8 domains: limitations in physical activities due to health problems, limitations in social activities due to physical or emotional problems; limitations in activities due to physical health problems; physical pain; general mental health; limitations in usual role activities due to emotional health; energy, and general health perceptions. Questions are scored and scaled (either positively or negatively) so that higher scores correspond to better health states.

\section{Statistical Analysis}

We defined probiotic users as individuals who responded "Yes" to the following question: "Do you take a probiotic regularly (at least 3 times a week)." We compared probiotic users to probiotic non-users with regard to the above-listed variables using Chi-square tests for categorical values and Student's t-tests or Mann-Whitney U test (for non-parametric data) for continuous variables. We then analyzed data via multiple logistic regression, reporting adjusted odds ratios and 95\% confidence intervals (CIs) to identify variables that were independently associated with probiotic use. After identifying significant differences on univariate analyses, we adjusted for the following variables in our multivariable analysis: age at diagnosis, gender, region, country, whether they sought nutritional counseling, primary information source, whether they keep to a strict GFD, whether they are still symptomatic, and how they were (serology, by biopsy, or by other test). We performed multiple logistic regression analysis both with and without significant SF-36 items to preserve power, as there were a limited number of respondents who answered all of the SF-36 questions. We used Stata version 16.0 (College Station, $\mathrm{Tx})$ for all calculations and statistical analysis.

\section{RESULTS}

We identified 4,909 patients that met criteria for inclusion in the study. Of these, $1,160(23.6 \%)$ patients responded to a question regarding probiotic use. The characteristics of our study population are shown in Table I. The subjects were predominantly female (82\%). The mean age was 38.8 years (SD \pm 17.4$) ; 3,879$ (79\%) were diagnosed with $\mathrm{CD}$ based on intestinal biopsy, serologies or both. The mean age at diagnosis was 32.2 ( $\mathrm{SD} \pm 6.4$ ) years; $85 \%$ of respondents were from the United States and the most common region of respondents $24.2 \%$ was in the Midwest; $38.6 \%$ of patients sought nutritional counseling at the time of diagnosis and $27.9 \%$ of patients use social media or an internet web page to obtain their primary information regarding celiac disease; $85 \%$ and $10.8 \%$ of respondents reported adhering to a strict GFD always or often, respectively. Notably, 50.4\% of respondents reported ongoing symptoms, despite adherence to a GFD, although further detail on the nature of these symptoms was not included in the survey. Of the patients that responded to the question 
regarding probiotic use $(\mathrm{n}=1,160), 381(32.8 \%)$ reported using probiotics to "aid in the digestion of gluten."

Table I. Baseline Characteristics

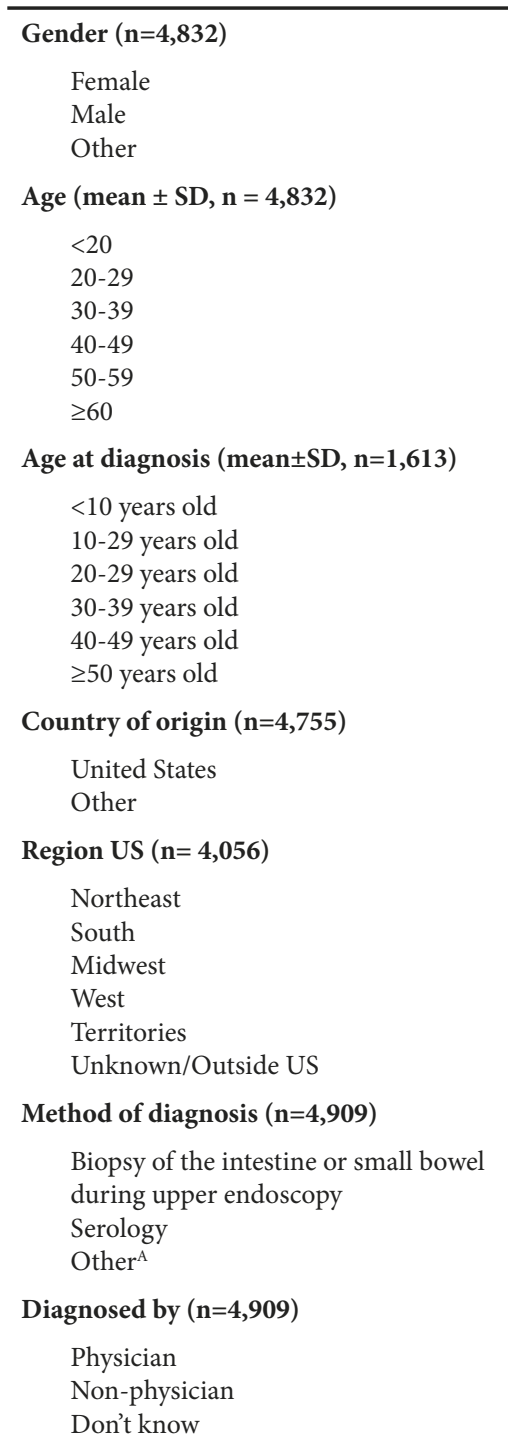

$3,958(81.9)$
$852(17.6)$
$22(0.5)$

$38.8 \pm 17.4$

$671(13.9)$

$942(19.5)$

$1,004(20.8)$

$863(17.9)$

$740(15.3)$

$612(12.7)$

$32.2 \pm 16.4$

$167(10.4)$

$200(12.4)$

$366(22.7)$

$353(21.9)$

265 (16.4)

$252(16.2)$

$4,172(85.0)$

$737(15.0)$

$1,043(21.3)$

$896(18.3)$

$1,190(24.2)$

$922(18.8)$

$5(0.1)$

$853(17.4)$

$3,081(62.8)$

$3,351(68.3)$

$1,498(30.5)$

$2,862(58.3)$

$150(3.1)$

1,897 (38.6)

At the time of diagnosis, I sought

nutritional counseling $(n=4,909)$

$\begin{array}{ll}\text { Yes } & 1,894(38.6) \\ \text { No } & 1,821(37.1) \\ \text { Don’t know } & 1,194(24.3)\end{array}$

Where do you obtain your primary

information about celiac disease? $(n=3,276)$

Physician

$691(14.1)$

Non-physician healthcare provider

238 (4.9)

$1,371(27.9)$

$155(3.2)$

$309(6.3)$

$310(6.3)$

1,835 (37.4)

Foundation or Support Group

Do not use information source

Don't know/Other

$62.5(13.5)$

Mean CD QOL Score $(\mathbf{n}=2981, \pm S D)$

I am just as healthy as anybody I know

$(n=679)$

$\begin{array}{ll}\text { Strongly Disagree } & 63(9.3) \\ \text { Somewhat Disagree } & 183(27.0) \\ \text { Neither Agree or Disagree } & 134(19.7) \\ \text { Somewhat Agree } & 222(32.7) \\ \text { Strongly Agree } & 77(11.3)\end{array}$

\begin{tabular}{ll}
\hline Table I (continued) & \\
\hline I keep a strict gluten free diet $(\mathbf{n}=\mathbf{3 , 6 2 5})$ & $3,082(85.0)$ \\
$\quad$ Always & $393(10.8)$ \\
Often & $81(2.2)$ \\
$\quad$ Sometimes & $34(0.9)$ \\
$\quad$ Rarely & $35(1.0)$ \\
$\quad$ Never & \\
I am still symptomatic despite keeping a & \\
Gluten free diet (n=2,456) & $1,238(50.4)$ \\
$\quad$ Yes & $837(34.1)$ \\
$\quad$ No & $381(15.5)$ \\
$\quad$ Don't know & \\
I use probiotics to aid in the digestion of \\
gluten (n=1,160) \\
$\quad$ Yes \\
$\quad$ No \\
\hline
\end{tabular}

Data are presented as N(\%) or mean $( \pm \mathrm{SD}) .{ }^{\mathrm{A}}$ Includes: Genetic testing, skin biopsy, gluten challenge, ALCAT food sensitivity test, stool test, allergy skin test, "other" tests.

We compared individuals who responded to the question regarding probiotic use with those who did not (Supplementary file, Table I) and found that respondents had similar age and gender distributions. However, non-respondents were more likely to be younger at the age of diagnosis and less likely to be over the age of 50 years at the time of diagnosis $(\mathrm{p}<0.001)$. There were also small regional variations in response, with individuals residing in the Midwest being more likely to respond to the probiotics question $(\mathrm{p}=0.001)$.

We compared patients who reported using probiotics $(n=381)$ to probiotic non-users $(n=779)$ in Table II. There were no significant differences between the two groups in current age, country of origin, or region inhabited. There were significant differences in both age at survey date and age of diagnosis ( $\mathrm{p}<0.001$ for both comparisons), with probiotic users representing older ages both at the time of survey completion and at diagnosis. There were no differences in the proportion of patients diagnosed by intestinal biopsy $(\mathrm{p}=0.23)$, serology $(p=0.70)$ or using other tests or means of diagnosis $(p=0.10)$ and no difference in probiotic use in those diagnosed by a physician versus a non-physician health care practitioner $(\mathrm{p}=0.18)$. Probiotic use, however, was also more common among those who reported that their primary information source was from a non-physician health care provider (41\%) compared to a physician (36\%) or those who did not have a primary information source $(17 \%, \mathrm{p}=0.002)$. Dietary adherence and self-reported health were similar among probiotic users and non-users.

Responses to the SF-36 scale are shown in Table III. There were no significant differences between the two groups in health change, general health, social functioning, emotional well-being, energy/fatigue, or role limitations due to emotional or physical health. Probiotic users experienced more physical pain ( 63.7 vs. $69.5, \mathrm{p}=0.006)$ and there was a non-significant trend toward reduced physical functioning in probiotic users (84.6 vs. 86.5, $\mathrm{p}=0.06$ ).

We subsequently performed multiple logistic regression analysis, shown in Table IV. After adjustment for all covariates in the model (gender, region, means of diagnosis, primary $\mathrm{CD}$ information source, country of origin, whether or not a 
Table II. Characteristics of Probiotic Users vs. Probiotic Non-Users

\begin{tabular}{|c|c|c|c|}
\hline Variable & $\begin{array}{l}\text { Probiotic Non-Users } \\
\qquad(\mathrm{n}=779)\end{array}$ & $\begin{array}{l}\text { Probiotic Users } \\
\quad(\mathrm{n}=381)\end{array}$ & $\mathrm{p}$ \\
\hline \multicolumn{4}{|l|}{ Gender } \\
\hline Male & $142(69.6)$ & $62(30.4)$ & \multirow[t]{2}{*}{0.38} \\
\hline Female & $630(66.4)$ & $319(33.6)$ & \\
\hline \multicolumn{4}{|l|}{ Age at survey date } \\
\hline$<20$ & $116(72.1)$ & $45(28.0)$ & \multirow[t]{6}{*}{$<0.001$} \\
\hline $20-29$ & $184(75.7)$ & $59(24.3)$ & \\
\hline $30-39$ & $164(66.9)$ & $81(33.1)$ & \\
\hline $40-49$ & $133(67.5)$ & $64(32.5)$ & \\
\hline $50-59$ & $110(61.8)$ & $68(38.2)$ & \\
\hline$\geq 60$ & $72(52.9)$ & $64(47.1)$ & \\
\hline \multicolumn{4}{|l|}{ Age at diagnosis } \\
\hline$\leq 10$ years old & $86(74.8)$ & $29(25.2)$ & \multirow[t]{6}{*}{$<0.001$} \\
\hline 11-19 years old & $103(81.8)$ & $23(18.3)$ & \\
\hline 20-29 years old & $190(70.1)$ & $81(29.9)$ & \\
\hline $30-39$ years old & $162(65.6)$ & $85(34.4)$ & \\
\hline $40-49$ years old & $120(65.2)$ & $64(34.8)$ & \\
\hline$>50$ years old & $113(53.6)$ & $98(46.5)$ & \\
\hline \multicolumn{4}{|l|}{ US region inhabited } \\
\hline Northeast & $178(68.2)$ & $83(31.8)$ & \multirow[t]{5}{*}{0.99} \\
\hline South & $152(66.7)$ & $76(33.3)$ & \\
\hline Midwest & $206(66.5)$ & $104(33.6)$ & \\
\hline West & $152(67.3)$ & $74(32.7)$ & \\
\hline Unknown/Outside US & $91(67.4)$ & $44(32.6)$ & \\
\hline \multicolumn{4}{|l|}{ Country of origin } \\
\hline United States & $693(67.1)$ & $340(32.9)$ & \multirow[t]{2}{*}{0.89} \\
\hline Other & $86(67.2)$ & $41(32.3)$ & \\
\hline \multicolumn{4}{|l|}{ Means of diagnosis } \\
\hline Biopsy of the intestine or small bowel during EGD & $586(68.1)$ & $274(31.9)$ & 0.23 \\
\hline Serology & $618(66.9)$ & $306(33.1)$ & 0.70 \\
\hline Other & $246(63.9)$ & $139(36.1)$ & 0.10 \\
\hline \multicolumn{4}{|l|}{ Diagnosed by } \\
\hline Physician & $609(68.7)$ & $277(31.3)$ & \multirow[t]{3}{*}{0.10} \\
\hline Non-physician & $22(57.9)$ & $16(42.1)$ & \\
\hline Unknown & $148(62.7)$ & $88(37.3)$ & \\
\hline \multicolumn{4}{|l|}{ Sought nutritional counseling at time of diagnosis } \\
\hline Yes & $357(63.8)$ & $203(36.3)$ & \multirow[t]{3}{*}{0.05} \\
\hline No & $411(70.1)$ & $175(29.9)$ & \\
\hline Don’t know & $7(70.0)$ & $3(30.0)$ & \\
\hline \multicolumn{4}{|c|}{ Where do you obtain your primary information about celiac disease? } \\
\hline Non-physician healthcare provider (dietitian, etc) & $56(59.0)$ & $39(41.1)$ & \multirow[t]{7}{*}{0.002} \\
\hline Physician & $177(63.9)$ & $100(36.1)$ & \\
\hline Social media/Internet web page & $310(68.9)$ & $140(31.1)$ & \\
\hline Other media (book, magazine) & $35(63.6)$ & $20(36.4)$ & \\
\hline Foundation or Support Group & $53(63.1)$ & $31(36.9)$ & \\
\hline Don't know & $47(61.0)$ & $30(39.0)$ & \\
\hline Do not use information source & $101(82.8)$ & $21(17.2)$ & \\
\hline Mean CD QOL Score $( \pm$ SD) & $62.8(15.1)$ & $61.6(15.3)$ & 0.2 \\
\hline I am just as healthy as anybody I know & & & \\
\hline Strongly disagree & $26(57.8)$ & $19(42.2)$ & 0.57 \\
\hline Somewhat disagree & $79(68.1)$ & $37(31.9)$ & \\
\hline Neither agree or disagree & $60(68.2)$ & $28(31.8)$ & \\
\hline Somewhat agree & $110(71.0)$ & $45(29.0)$ & \\
\hline Strongly agree & $40(70.2)$ & $17(29.8)$ & \\
\hline I keep a strict gluten free diet & & & \\
\hline Always & $668(66.2)$ & $341(33.8)$ & 0.087 \\
\hline Often & $75(70.1)$ & $32(29.9)$ & \\
\hline Sometimes & $17(70.8)$ & $7(29.2)$ & \\
\hline Rarely & $7(100)$ & $0(0)$ & \\
\hline Never & $12(92.3)$ & $1(7.7)$ & \\
\hline
\end{tabular}




\begin{tabular}{l}
\hline Table II (continued) \\
\hline I am still symptomatic despite keeping a gluten free diet \\
Yes \\
No \\
Don't know \\
Data are presented as N(\%) or mean ( \pm SD). Bolded values are p-values at level of significance $<0.05$. P-values for difference \\
amongst categories were obtained from Chi-square, Student's T test, or Mann-Whitney U Test.
\end{tabular}

nutritionist was sought at time of diagnosis, GFD adherence, age at diagnosis, and whether or not patients remain symptomatic despite adherence to a GFD), probiotic users were twice as likely to have been diagnosed over the age of 50 ( $\mathrm{aOR}=2.04$, 95\% CI: 1.37-3.04) and half as likely to be diagnosed between the ages of $11-19(\mathrm{aOR}=0.50,95 \% \mathrm{CI}: 0.29-0.85)$ as compared to those diagnosed between the ages of 20-29. Patients who did not use any primary information source were less likely to use probiotics as compared to those whose physicians served as their primary source of information $(\mathrm{aOR}=0.42$ 95\%CI: 0.24-0.73). Patients who remained symptomatic despite adherence to a GFD were almost twice as likely to use probiotics $(\mathrm{aOR}=1.94,95 \% \mathrm{CI}$ : 1.44-2.63). Given that few survey participants responded to questions regarding the SF$36(n=683)$ we chose to omit the findings from the primary multivariable model. However, when the pain subscale of the SF-36 was incorporated into the model (Supplementary file, Table II), there was an increased likelihood of probiotic use with pain scale sub-scores below 90, with the highest odds of probiotic use $(\mathrm{aOR}=4.01,95 \% \mathrm{CI}$ : $1.44-11.14)$ in respondents in the lowest quartile (corresponding to scores $0-45$, the greatest degree of physical pain experienced).

\section{DISCUSSION}

Patients with CD commonly use supplements including probiotics for perceived health benefits. While numerous studies have investigated their use in other gastrointestinal disease, such as inflammatory bowel disease and Clostridium difficile infection [14-20], little is known about probiotic use in CD. A recent meta-analysis by Seiler et al. [21] of seven studies, including six randomized controlled trials suggests a statistically significant symptom benefit of probiotic use when measured by the Gastrointestinal Symptom Rating Scale, but not when other questionnaires were employed with evidence certainty rated as very low to low. In this large study of a national CD registry, about one third of CD patients reported using probiotic supplements. We identified three statistically significant predictors of probiotic use on multivariable analysis: age at diagnosis, the persistence of symptoms despite maintaining a GFD, and not reporting a primary information source when learning about CD.

We found that patients diagnosed with $\mathrm{CD}$ at age 50 or later were twice as likely to use probiotics. It is possible that this finding simply reflects temporal trends in the general population in which probiotic use has steadily increased since 2007 [8]. Other explanations may be related to the differences in CD presentation with age. Several studies have shown agerelated differences in clinical and histological features of CD at initial diagnosis. For example, Vivas et al. [22] demonstrated that the delay between symptom onset and CD diagnosis increases with age, a finding the authors attributed to a lower disease awareness among adult healthcare professionals and the atypical clinical presentation among adults. One possible explanation for our finding may therefore be that patients diagnosed later in life have been symptomatic and/ or misdiagnosed for a longer period of time and may be more likely to have tried probiotics or other supplements for relief. Age-related differences in symptom management may also play a role; a large, retrospective study conducted by Jericho et al. [23] found that children adherent to a strict GFD had faster and higher rates of improvement in gastrointestinal and extraintestinal symptoms as compared to adults. The higher use of probiotics among adults diagnosed later in life may therefore be attributed to a greater need for alternative methods of symptom control.

Patients who denied using any information source (such as healthcare providers, online media or support groups) to obtain primary information about CD were significantly less likely to use probiotics than patients who utilized one or more sources. This association may be as a result of the rising popularity of complementary and alternative medical

Table III. SF-36 Scores in Probiotic Users vs. Probiotic Non-Users $(n=683)$

\begin{tabular}{lcccc}
\hline SF-36 Scale & $\begin{array}{c}\text { Overall Mean } \\
( \pm \text { SD })\end{array}$ & $\begin{array}{c}\text { Probiotic Non- } \\
\text { Users Mean }( \pm \mathrm{D})\end{array}$ & $\begin{array}{c}\text { Probiotic Users } \\
\text { Mean }( \pm \mathrm{D})\end{array}$ & p value \\
\hline Physical functioning & $85.9(18.4)$ & $86.5(19.9)$ & $84.6(17.4)$ & 0.06 \\
Role limitations due to physical health & $68.2(39.6)$ & $69.6(39.5)$ & $64.6(40.1)$ & 0.19 \\
Role limitations due to emotional health & $52.8(43.4)$ & $54.5(43.2)$ & $48.4(42.9)$ & 0.13 \\
Energy/fatigue & $43(20.6)$ & $43.9(21.7)$ & $41.7(19.9)$ & 0.28 \\
Emotional well-being & $60.9(17.4)$ & $60.7(17.8)$ & $62.8(16.4)$ & 0.29 \\
Social functioning & $72.6(24.1)$ & $73.1(25.0)$ & $74.2(23.2)$ & 0.83 \\
Pain & $67.1(21.7)$ & $69.5(22.1)$ & $63.7(21.6)$ & $\mathbf{0 . 0 0 6}$ \\
General health & $53.6(22.1)$ & $55.6(21.9)$ & $52.2(23.4)$ & 0.13 \\
Health change & $58.1(23.8)$ & $57.6(22.4)$ & $61.3(27.4)$ & 0.11 \\
\hline
\end{tabular}


Table IV. Independent predictors of probiotic usage among celiac disease patients ${ }^{*}$

\begin{tabular}{|c|c|c|}
\hline Variables & OR $(95 \% \mathrm{CI})$ & $\mathrm{p}$ \\
\hline \multicolumn{3}{|l|}{ Gender } \\
\hline Male & ref & \\
\hline Female & $1.30(0.91-1.86)$ & 0.14 \\
\hline \multicolumn{3}{|l|}{ Age at Diagnosis } \\
\hline$\leq 10$ years old & $0.86(0.50-1.47)$ & 0.58 \\
\hline $11-19$ years old & $0.50(0.29-0.85)$ & 0.011 \\
\hline $20-29$ years old & ref & -- \\
\hline $30-39$ years old & $1.22(0.83-1.80)$ & 0.31 \\
\hline $40-49$ years old & $1.27(0.84-1.93)$ & 0.26 \\
\hline$>50$ years old & $2.04(1.37-3.04)$ & $<0.001$ \\
\hline \multicolumn{3}{|c|}{ Where do you obtain your primary information about celiac disease? } \\
\hline Non-physician healthcare provider (i.e. dietician) & $1.00(0.60-1.66)$ & 0.99 \\
\hline Physician & ref & -- \\
\hline Social media/Internet web page & $0.74(0.52-1.04)$ & 0.78 \\
\hline Other media (book, magazine) & $0.77(0.41-1.46)$ & 0.43 \\
\hline Foundation or Support Group & $0.90(0.53-1.54)$ & 0.71 \\
\hline Don't know & $1.16(0.67-2.03)$ & 0.59 \\
\hline Do not use information source & $0.42(0.24-0.73)$ & 0.002 \\
\hline \multicolumn{3}{|l|}{ At the time of diagnosis, I sought nutritional counseling } \\
\hline Yes & $1.24(0.95-1.63)$ & 0.12 \\
\hline No & ref & -- \\
\hline Don’t know & $0.66(0.13-3.39)$ & 0.61 \\
\hline \multicolumn{3}{|l|}{ I am still symptomatic despite keeping a gluten free diet } \\
\hline Yes & $1.94(1.44-2.63)$ & $<0.001$ \\
\hline No & ref & -- \\
\hline Don't know & $1.18(0.79-1.78)$ & 0.42 \\
\hline
\end{tabular}

therapy, and the popularity of the GFD in that field [24]. The fact that those who relied on non-physician healthcare providers (including dietitians) were similar to those who relied on physicians for their advice may be due to the central role of the dietitian in the management of CD. It is important to note that the questionnaire in this study did not distinguish whether probiotic use among participants was prescribed or recommended by a physician; that said, a recent study by O'Connor et al. [25] showed that over $65 \%$ of probiotic use is self-initiated rather than guided by a physician recommendation.

One important finding in this study is that patients who remain symptomatic despite adhering to a strict GFD are twice as likely to use probiotics as those who achieve symptom resolution. This finding suggests that patients may be seeking additional means of treatment for persistent symptoms. Few human studies have examined the potential for clinical benefit with probiotic use in CD. In an exploratory, randomized controlled trial studying the effects of Bifidobacterium infantis natren life start strain on patients with untreated CD, patients in the treatment group experienced a significant improvement in gastrointestinal symptoms compared to controls despite no difference in intestinal permeability [26]. Similarly, a randomized controlled study of a multispecies probiotic mixture of 5 strains of Lactobacillus and Bifidobacterium revealed an improvement in severity of IBS-type symptoms in CD patients adherent to a strict GFD [27]. Despite these encouraging findings, studies of other strains, including one on Bifidobacterium longum CECT 7347 and another on VSL \#3 (a blend of Streptococcus, Bifidobacterium, and Lactobacillus species) did not demonstrate any significant improvement in symptoms between treatment and control groups [28, 29]. Regardless of any actual benefit, our findings suggest that patients with uncontrolled CD symptoms may perceive probiotics as a potential adjunctive treatment.

To our knowledge, this study is one of the first to investigate the prevalence and predictors of probiotic use among $\mathrm{CD}$ patients. Other strengths include the large number of participants $(4,909$ with 1,160 patients responding to a question regarding probiotic use) and the broad, nationwide scope of the study survey. We also recognize several limitations of this study. First, the study data was obtained from a voluntary survey in a patient-powered research network and is therefore prone to selection bias; participants may have greater selfawareness and attention to their symptoms than the general $\mathrm{CD}$ population. Furthermore, as patients who were diagnosed with CD after the age of 50 years were more likely to respond to the question regarding probiotic use, it is possible that there is a selection bias which led to this finding. Our study was also limited to a low number of individuals who responded (24\%) to our question of interest regarding probiotic use. This question was added to the survey in August of 2017, more than 18 months after the launch of the PPRN. Therefore, a significant number of participants who filled out the survey prior to 
this date did not have the option to answer this question. Quantification of probiotic use (i.e. daily, thrice weekly, etc) was not included in the questionnaire, precluding the ability for a dose-response analysis. Use of self-reported data in this study, particularly self-reported CD status, also limits the generalizability and internal validity of its findings given that the data is only as accurate as the participant's ability to recall prior events. Additionally, the retrospective design of this study limits the ability to draw conclusions about whether probiotic use itself has any effect on symptoms or quality of life and as we did not correct for multiple comparisons, the significant findings in this cross-sectional analysis should be regarded as hypothesis-generating.

\section{CONCLUSIONS}

This analysis of data obtained through a national CD registry demonstrated that probiotic use is common among patients with $\mathrm{CD}$ and is associated with older age at diagnosis. Those who remained symptomatic despite a GFD were twice as likely to take probiotics, compared with those reporting symptom control. Patients who reported the most pain were also the most likely to take probiotics. These findings suggest that patients may be seeking additional means of treatment for persistent symptoms. Further study is needed to clarify whether or not these symptoms are related to accidental gluten ingestion and to evaluate any benefit of using probiotics in symptoms or quality of life in people with CD.

Conflicts of interest: None to declare.

Authors' contributions: A.M.J., B.L., M.G., P.H.G. conceived and designed the study. A.M.J., R.M.C. collected data. A.M.J., J.W.B. analyzed data. AMJ, AMC drafted the manuscript. AMJ, A.M.C., M.G., J.W.B., R.M., B.L., P.H.G. revised the manuscript.

Acknowledgements: Grand support for BL: the Louis and Gloria Flanzer Philanthropic Trust.

Supplementary material: To access the supplementary material visit the online version of the J Gastrointestin Liver Dis at http://dx.doi. org/10.15403/jgld-3814

\section{REFERENCES}

1. Lebwohl B, Sanders DS, Green PHR. Coeliac disease. Lancet 2018;391:70-81. doi:10.1016/S0140-6736(17)31796-8

2. Rubio-Tapia A, Ludvigsson JF, Brantner TL, Murray JA, Everhart JE. The prevalence of celiac disease in the United States. Am J Gastroenterol 2012;107:1538-1544. doi:10.1038/ajg.2012.219

3. Choung RS, Larson SA, Khaleghi S, et al. Prevalence and morbidity of undiagnosed celiac disease from a community-based study. Gastroenterology 2017;152:830-839.e5. doi:10.1053/j. gastro.2016.11.043

4. Paarlahti P, Kurppa K, Ukkola A, et al. Predictors of persistent symptoms and reduced quality of life in treated coeliac disease patients: a large cross-sectional study. BMC Gastroenterol 2013;13:75. doi:10.1186/1471-230X-13-75
5. Roos S, Liedberg GM, Hellström I, Wilhelmsson S. Persistent Symptoms in People With Celiac Disease Despite Gluten-Free Diet: A Concern? Gastroenterol Nurs 2019;42:496-503. doi:10.1097/ SGA.0000000000000377

6. Leffler DA, Kelly CP, Green PH, et al. Larazotide acetate for persistent symptoms of celiac disease despite a gluten-free diet: a randomized controlled trial. Gastroenterology 2015;148:1311-1319.e6. doi:10.1053/j. gastro.2015.02.008

7. Nazareth S, Lebwohl B, Tennyson CA, Simpson S, Greenlee H, Green $\mathrm{PH}$. Dietary supplement use in patients with celiac disease in the United States. J Clin Gastroenterol 2015;49:577-581. doi:10.1097/ MCG.0000000000000218

8. Su GL, Ko CW, Bercik P, et al. AGA clinical practice guidelines on the role of probiotics in the management of gastrointestinal disorders. Gastroenterology 2020;159:697-705. doi:10.1053/j.gastro.2020.05.059

9. Plaza-Diaz J, Ruiz-Ojeda FJ, Gil-Campos M, Gil A. Mechanisms of Action of Probiotics. Adv Nutr 2019;10(suppl_1):S49-S66. doi:10.1093/ advances/nmy063

10. Valitutti F, Cucchiara S, Fasano A. Celiac Disease and the Microbiome. Nutrients 2019;11:2403. doi:10.3390/nu11102403

11. Chibbar R, Dieleman LA. The Gut Microbiota in Celiac Disease and probiotics. Nutrients 2019;11:2375. doi:10.3390/nu11102375

12. Dorn SD, Hernandez L, Minaya MT, et al. The development and validation of a new coeliac disease quality of life survey (CD-QOL) Aliment Pharmacol Ther 2010;31:666-675. doi:10.1111/j.13652036.2009.04220.x

13. Ware JE Jr, Sherbourne CD. The MOS 36-item short-form health survey (SF-36): I. Conceptual framework and item selection. Med Care 1992;30:473-483.

14. Rembacken BJ, Snelling AM, Hawkey PM, Chalmers DM, Axon AT. Non-pathogenic Escherichia coli versus mesalazine for the treatment of ulcerative colitis: a randomised trial. Lancet 1999;354:635-639. doi:10.1016/s0140-6736(98)06343-0

15. Matthes H, Krummenerl T, Giensch M, Wolff C, Schulze J. Clinical trial: probiotic treatment of acute distal ulcerative colitis with rectally administered Escherichia coli Nissle 1917 (EcN). BMC Complement Altern Med 2010;10:13. doi:10.1186/1472-6882-10-13

16. Petersen AM, Mirsepasi H, Halkjær SI, Mortensen EM, NordgaardLassen I, Krogfelt KA. Ciprofloxacin and probiotic Escherichia coli Nissle add-on treatment in active ulcerative colitis: a doubleblind randomized placebo controlled clinical trial. J Crohns Colitis 2014;8:1498-1505. doi:10.1016/j.crohns.2014.06.001

17. Allen SJ, Wareham K, Wang D, et al. Lactobacilli and bifidobacteria in the prevention of antibiotic-associated diarrhoea and Clostridium difficile diarrhoea in older inpatients (PLACIDE): a randomised, double-blind, placebo-controlled, multicentre trial. Lancet 2013;382:1249-1257. doi:10.1016/S0140-6736(13)61218-0

18. Plummer S, Weaver MA, Harris JC, Dee P, Hunter J. Clostridium difficile pilot study: effects of probiotic supplementation on the incidence of C. difficile diarrhoea. Int Microbiol 2004;7:59-62.

19. Pozzoni P, Riva A, Bellatorre AG, et al. Saccharomyces boulardiifor the Prevention of Antibiotic-Associated Diarrhea in Adult Hospitalized Patients: A Single-Center, Randomized, Double-Blind, PlaceboControlled Trial. Am J Gastroenterol 2012;107:922-931. doi:10.1038/ ajg.2012.56

20. Surawicz CM, Elmer GW, Speelman P, McFarland LV, Chinn J, van Belle G. Prevention of antibiotic-associated diarrhea by Saccharomyces boulardii: a prospective study. Gastroenterology 1989;96:981-988. doi:10.1016/0016-5085(89)91613-2 
21. Seiler CL, Kiflen M, Stefanolo JP, et al. Probiotics for Celiac Disease: A Systematic Review and Meta-Analysis of Randomized Controlled Trials. Am J Gastroenterol 2020;115:1584-1595. doi:10.14309/ ajg.0000000000000749

22. Vivas S, Vaquero L, Rodríguez-Martín L, Caminero A. Age-related differences in celiac disease: Specific characteristics of adult presentation. World J Gastrointest Pharmacol Ther 2015;6:207-212. doi:10.4292/wjgpt.v6.i4.207

23. Jericho H, Sansotta N, Guandalini S. Extraintestinal Manifestations of Celiac Disease: Effectiveness of the Gluten-Free Diet. J Pediatr Gastroenterol Nutr 2017;65:75-79. doi:10.1097/MPG.0000000000001420

24. Boyer G, Caulfield T, Green PHR, Lebwohl B. Promotion of testing for celiac disease and the gluten-free diet among complementary and alternative medicine practitioners. Am J Gastroenterol 2019;114:786791. doi:10.14309/ajg.0000000000000238

25. O'Connor LE, Gahche JJ, Herrick KA, Davis CD, Potischman N, Vargas AJ. Nonfood Prebiotic, Probiotic, and Synbiotic Use Has Increased in US Adults and Children From 1999 to 2018. Gastroenterology 2021 Apr 23. doi:10.1053/j.gastro.2021.04.037
26. Smecuol E, Hwang HJ, Sugai E, et al. Exploratory, randomized, doubleblind, placebo-controlled study on the effects of Bifidobacterium infantis natren life start strain super strain in active celiac disease. J Clin Gastroenterol 2013;47:139-147. doi:10.1097/ MCG.0b013e31827759ac

27. Francavilla R, Piccolo M, Francavilla A,et al. Clinical and microbiological effect of a multispecies probiotic supplementation in celiac patients with persistent IBS-type symptoms: a randomized, double-blind, placebo-controlled, multicenter trial. J Clin Gastroenterol 2019;53:e117-e125. doi:10.1097/ MCG.0000000000001023

28. Olivares M, Castillejo G, Varea V, Sanz Y. Double-blind, randomised, placebo-controlled intervention trial to evaluate the effects of Bifidobacterium longum CECT 7347 in children with newly diagnosed coeliac disease. Br J Nutr 2014;112:30-40. doi:10.1017/ S0007114514000609

29. Harnett J, Myers SP, Rolfe M. Probiotics and the Microbiome in Celiac Disease: A Randomised Controlled Trial. Evid Based Complement Alternat Med 2016;2016:9048574. doi:10.1155/2016/9048574 